\title{
Phosphatidylinositol 3-Kinase Is Required for the Expression But Not for the Induction or the Maintenance of Long-Term Potentiation in the Hippocampal CA1 Region
}

\author{
Pietro Paolo Sanna, ${ }^{1}$ Maurizio Cammalleri, ${ }^{1,2}$ Fulvia Berton, ${ }^{1,2}$ Cindy Simpson, ${ }^{1}$ Robert Lutjens, ${ }^{1}$ \\ Floyd E. Bloom, ${ }^{1}$ and Walter Francesconi ${ }^{1,2}$ \\ 'Department of Neuropharmacology, The Scripps Research Institute, La Jolla, California 92037, and 2Universita' degli \\ Studi Di Pisa, Dipartimento di Fisiologia e Biochimica "G. Moruzzi”, Pisa, Italy 56127
}

\begin{abstract}
Several signal transduction pathways have been implicated in the induction of long-term potentiation (LTP), yet the signal transduction mechanisms behind the maintenance-expression phase of LTP are still poorly understood. We investigated the role of phosphatidylinositol 3-kinase (PI3-kinase) in LTP at Schaffer collateral/commissural fiber-CA1 synapses in rat hippocampal slices using biochemical approaches and extracellular electrophysiological recordings. We observed that PI3kinase activity was induced in the CA1 region during LTP of field EPSPs (fEPSPs) and that two structurally unrelated PI3-kinase inhibitors, LY294002 and wortmannin, abated established LTP, suggesting that PI3-kinase is involved in the maintenanceexpression phase of LTP. However, LTP recovered after washout of the reversible PI3-kinase inhibitor LY294002, confirming
\end{abstract}

Activity-dependent synaptic changes are believed to be crucial in learning and memory. Long-term potentiation (LTP) of EPSPs is a long-lasting increase of synaptic strength that can be induced with tetanic stimulation of afferent fibers (Malenka and Nicoll, 1999). At Schaffer collateral/commissural fiber-CA1 synapses, LTP is characterized by a persistent enhancement of the responses of AMPA-sensitive glutamatergic receptors (Malenka and Nicoll, 1999; Malinow et al., 2000). Such an enhancement is currently believed to be primarily attributable to increased postsynaptic density of AMPA receptors (Malenka and Nicoll, 1999; Luscher et al., 2000; Malinow et al., 2000). Induction of LTP is triggered by an initial elevation of cytosolic calcium to which both NMDA receptors and L-type voltage-dependent calcium channels (VDCC) can contribute (Teyler et al., 1994; Malenka and Nicoll, 1999). Multiple signal transduction pathways are then recruited to translate the $\mathrm{Ca}^{2+}$ signal into increased synaptic strength, including $\alpha$-calcium/calmodulin-dependent protein kinase II (CaMKII), which is believed to play a pivotal role (Malenka and Nicoll, 1999). However, although prevailing views implicate CaMKII also in the maintenance-expression of

Received Oct. 29, 2001; revised Feb. 1, 2002; accepted Feb. 4, 2002.

This study was supported in part by National Institutes of Health Grants MH62140 and MH64376 (P.P.S. and W.F.) and P50AA06420 (F.E.B. and P.P.S.). We are grateful to Drs. George Siggins, Paul Schweitzer, and Steven Henriksen (from The Scripps Research Institute) for critical review of this manuscript and Dr. George Koob (also from The Scripps Research Institute) for his support and encouragement.

Correspondence should be addressed to Pietro Paolo Sanna or Walter Francesconi, Department of Neuropharmacology, The Scripps Research Institute, 10550 N. Torrey Pines Road, La Jolla, CA 92037. E-mails: psanna@scripps.edu and wfranc@scripps.edu.

Copyright (C) 2002 Society for Neuroscience $0270-6474 / 02 / 223359-07 \$ 15.00 / 0$ that LTP maintenance and expression are distinct events and indicating that PI3-kinase activity is required for LTP expression rather than for its maintenance. Interestingly, preincubation with LY294002 did not prevent LTP induction. In fact, if LY294002 was withdrawn 5 min after high-frequency stimulation, an LTP of fEPSP was seen. Last, a voltage-dependent calcium channel-dependent form of LTP in the CA1 could also be reversibly abated by LY294002, raising the possibility that PI3kinase could be required for the expression of multiple forms of synaptic potentiation.

Key words: long-term potentiation; synaptic plasticity; hippocampus; PI3-kinase; signal transduction; NMDA; voltagedependent calcium channels; AMPA

LTP, specific inhibitors of CaMKII do not abate LTP when applied after its induction (Malinow et al., 1989; Ito et al., 1991; Bortolotto and Collingridge, 1998; Chen et al., 2001) nor do inhibitors of other kinases implicated in LTP, such as mitogenactivated protein kinase (MAPK) and Src (English and Sweatt, 1997; Salter, 1998). These observations suggest that distinct signal transduction events could be involved in the induction and in the maintenance-expression phases of LTP. A distinction has also been proposed between the maintenance and the expression of LTP (Malinow et al., 1988). In fact, it has been observed that the wide-spectrum kinase inhibitor H-7 can abate established LTP in a reversible manner, suggesting that the molecular mechanisms underlying the maintenance of LTP are not affected by this inhibitor, despite the inhibition of LTP expression (Malinow et al., 1988). A late phase of LTP has also been identified that is protein kinase A (PKA) dependent and requires de novo gene expression (Frey et al., 1993; Huang, 1998).

In the present study, we investigated the role of phosphatidylinositol 3-kinase (PI3-kinase) (Whitman et al., 1988; Wymann and Pirola, 1998; Leevers et al., 1999) in the early phase of LTP at Schaffer collateral/commissural fiber-CA1 synapses using biochemical and electrophysiological approaches. PI3-kinase phosphorylates the D-3 position of the inositol ring of phosphoinositides (PtdIns) (Whitman et al., 1988), which are also the precursors for the second messengers phosphoinositols and diacylglycerol (Clapham, 1995). Current views suggest that D-3-phosphorylated PtdIns act as membrane-embedded second messengers in the regulation of a broad array of biological functions (Whitman et al., 1988; Wymann and Pirola, 1998; Leevers et al., 1999). Among PI3-kinase downstream effectors are phosphoinositide-dependent 
kinases 1 (PDK1) and the members of the AGC subfamily of protein kinases Akt (also known as protein kinase B), p70 ${ }^{\mathrm{s} 6 \mathrm{k}}$, and atypical protein kinase $\mathrm{C}$ isozymes, such as $\mathrm{PKC} \zeta$ (Whitman et al., 1988; Wymann and Pirola, 1998; Leevers et al., 1999). PDK1 is involved in the activation of other PI3-kinase targets, including Akt and $\mathrm{p} 70^{\mathrm{S} 6 \mathrm{k}}$, which are believed to mediate most of the PI3-kinase effects (Franke et al., 1997; Chou et al., 1998; Chan et al., 1999; Romanelli et al., 1999).

\section{MATERIALS AND METHODS}

Hippocampal slice preparations and electrophysiological techniques. Hippocampal slices were prepared as described previously (Sanna et al., 2000). Briefly, we killed Wistar rats (28-35 d of age) by decapitation under halothane (3\% in air) anesthesia. The brains were then rapidly removed and transferred into ice-cold artificial CSF (ACSF) [in mM: 130 $\mathrm{NaCl}, 3.5 \mathrm{KCl}, 24 \mathrm{NaHCO}, 1.25 \mathrm{NaH}_{2} \mathrm{PO}_{4}, 2.2 \mathrm{CaCl} 2,10$ glucose, and $2 \mathrm{MgSO}_{4}, \mathrm{pH} 7.4$ (oxygenated by bubbling a mixture of $95 \% \mathrm{O}_{2}-$ $\left.5 \% \mathrm{CO}_{2}\right)$ ] and sliced with a Leica (Wetzlar, Germany) VT1000E automatic vibratome slicer to obtain transverse hippocampal slices $(400 \mu \mathrm{m})$. Hippocampal slices were collected in oxygenated ACSF and preincubated for at least $1 \mathrm{hr}$ at room temperature. For recording, slices were transferred to a submerged recording chamber, perfused with oxygenated ACSF, and maintained at $31 \pm 1^{\circ} \mathrm{C}$. They were further incubated for at least $40 \mathrm{~min}$ before the recording session. The flow was maintained at $1.2 \mathrm{ml} / \mathrm{min}$ in a chamber volume of $1.5 \mathrm{ml}$. Drug applications were performed by changing the chamber infusion to ACSF containing the agent. Microelectrodes, pulled from 1.5-mm-outer diameter glass tubing with the use of a Flaming/Brown micropipette puller (Sutter Instruments, Novato, CA), were filled with ACSF (resistance of 3-5 M $\Omega$ ). Bipolar stimulating electrodes were placed in the stratum radiatum to activate the Schaffer collateral/commissural fibers (see below, LTP paradigms). Recordings of field EPSPs (fEPSPs) were made in the middle of the stratum radiatum with an Axoclamp 2B (Axon Instruments, Foster City, CA). Test intensities were set to obtain fEPSP slopes of $\sim 50 \%$ of those at which population spikes were detectable based on input-output curves obtained in each slice. An average of five stimulus-evoked responses was collected every $3 \mathrm{~min}$. As an indicator of synaptic efficacy, we measured the initial slope of the rising phase of the fEPSP because it is not affected by population spikes or altered by EPSP-spike (E-S) potentiation (Abraham et al., 1987). The initial slope of fEPSP was measured near its onset for an interval of $1.2 \mathrm{msec}$. The acquisition and analysis were performed with the LABVIEW software package (National Instruments, Austin, TX). Intracellular recordings were made using glass micropipettes filled with 2 M K-acetate, $\mathrm{pH} 7.3$ (80-120 M $\Omega$ ). Cells with stable resting membrane potentials (r.m.p.) during the recording section were selected (r.m.p., $-67.4 \pm 0.75 \mathrm{mV}$; input resistance, $36 \pm$ $5.1 \mathrm{M} \Omega ; n=5$ ). Stimuli of $0.08 \mathrm{msec}$ duration and $0.9 \pm 0.05 \mathrm{~mA}$ intensity were applied once every $20 \mathrm{sec}$ to the Schaffer collateral/ commissural fibers to evoke EPSPs NMDA. Before each synaptic activation, the input resistance was measured injecting into the cell a pulse of current $(200 \mathrm{msec},-0.2 \mathrm{nA})$. The bridge balance and r.m.p. were carefully adjusted as needed. All of the data presented were obtained in slices from multiple animals

LTP paradigms. fEPSPs were recorded for at least $20 \mathrm{~min}$ before high-frequency stimulation (HFS) to ensure stability of excitability. fEPSP slopes were normalized as the percentage of mean fEPSP over such period of time. fEPSPs at the time point preceding HFS were used as the basal fEPSP level. A two-pathway paradigm was used in which two stimulating electrodes were placed in the stratum radiatum on opposite sides of the recording electrode to stimulate two separate groups of Schaffer collateral/commissural fibers. The pathway stimulated by the electrode on the medial side of the stratum radiatum was designated as $\mathrm{S} 1$, and the pathway stimulated by the electrode on the lateral (fimbrial) side was called S2. The independence of the two pathways was demonstrated by the absence of paired-pulse facilitation of fEPSP when two sets of orthodromic stimuli ( $0.08 \mathrm{msec}$ duration) were delivered to the two pathways at $40 \mathrm{msec}$ interval (in either order, S1-S2 or S2-S1); however, paired-pulse facilitation of fEPSP was observed when the stimuli were applied to the same electrode. Independence of the two pathways was also demonstrated by the lack of potentiation in the untetanized pathway (S1) after induction of LTP to the tetanized one (S2). Test stimuli were delivered at one per $15 \mathrm{sec}$. For LTP induction, two trains of $500 \mathrm{msec}$ duration each at $100 \mathrm{~Hz}$ with an interval of $10 \mathrm{sec}$ at the test intensity were delivered to one of the pathways. Results obtained with the twopathway paradigm were confirmed in a single pathway paradigm and by inverting the order of stimulation of the two pathways. Some experiments (see Fig. 2) were performed in the single-pathway paradigm in the same manner. An L-type VDCC-dependent LTP was obtained in the CA1 with 10 trains of $200 \mathrm{~Hz}$, each $200 \mathrm{msec}$ long, delivered at $5 \mathrm{sec}$ intervals in the presence of D-AP-5 $(50 \mu \mathrm{M})$ and bicuculline $(10 \mu \mathrm{M})$, as described by Grover and Yan (1999). LY294002, wortmannin, nifedipine, and D-AP-5 were obtained from Calbiochem (San Diego, CA). We operationally define as interfering with LTP induction treatments that can prevent LTP only when applied during tetanic stimulation but that do not abate established LTP. Conversely, we define as interfering with LTP expression treatments capable of reversibly abating established LTP after tetanic stimulation, whereas only a treatment with a reversible mechanism of action that would permanently abate LTP could be seen as an inhibitor of LTP maintenance.

Kinase assay and Western blotting. The PI3-kinase assay was performed as described previously (Macara et al., 1984; Alessi et al., 1996), with minor modifications. We obtained tissue extract by sonication of CA1 hippocampal regions in $50 \mu \mathrm{l}$ of lysis buffer containing $10 \mathrm{~mm}$ Tris-HCl, $\mathrm{pH} 7.6,50 \mathrm{~mm} \mathrm{NaCl}, 30 \mathrm{~mm} \mathrm{Na}_{4} \mathrm{P}_{2} \mathrm{O}_{7}, 1 \% \mathrm{NP}-40$, and protease $(10 \mu \mathrm{g} / \mathrm{ml}$ leupeptin, $2.5 \mu \mathrm{l} / \mathrm{ml}$ aprotinin, and $1 \mathrm{~mm}$ PMSF) and phosphatase inhibitors $\left(20 \mathrm{~mm} \mathrm{NaF}\right.$ and $1 \mathrm{~mm}$ activated $\mathrm{Na}_{3} \mathrm{VO}_{4}$ ). Homogenized samples were clarified by centrifugation for $10 \mathrm{~min}$ at $15,000 \mathrm{rpm}$ at $4^{\circ} \mathrm{C}$. PI3kinase activity was analyzed in immunoprecipitates obtained with $5 \mu$ l of an anti-phosphotyrosine antibody (Sigma, St. Louis, MO) performed at $4^{\circ} \mathrm{C}$ with gentle shaking, using an agarose-conjugated goat anti-mouse antiserum (Sigma). The PI3-kinase reaction mixture contained $20 \mathrm{~mm}$ HEPES, $10 \mathrm{~mm} \mathrm{MgCl}, 100 \mu \mathrm{M} \mathrm{Na}_{3} \mathrm{VO}_{4}, 40 \mu \mathrm{M}$ cold ATP, $3.5 \mu \mathrm{l}$ of $\left[\gamma^{-32} \mathrm{P}\right]$ ATP $(1 \mathrm{mCi}, 3000 \mathrm{Ci} / \mathrm{mmol}$; NEN, Boston, MA), and $0.3 \mu \mathrm{g}$ of PI (Avanti, Alabaster, AL) from a stock prepared in $50 \mathrm{~mm}$ HEPES, $1 \mathrm{~mm}$ EDTA, $\mathrm{pH} 7.0$, and $0.5 \% \mathrm{w} / \mathrm{v}$ cholic acid, after drying under a stream of $\mathrm{N}_{2}$. After incubation at room temperature for $20 \mathrm{~min}$, reactions were stopped with $114 \mu \mathrm{l}$ of $2.4 \mathrm{M} \mathrm{HCl}$ in $50 \% \mathrm{MeOH}$. Phospholipids were then extracted in $50 \mu \mathrm{l}$ of chloroform separated by thin-layer chromatography (TLC) on plates (Whatman, Clifton, NJ) prerun for $3 \mathrm{hr}$ with $1.2 \%$ potassium oxalate $\left(\mathrm{C}_{2} \mathrm{O}_{4} \mathrm{~K}_{2}\right) \mathrm{w} / \mathrm{v}$ in $50 \% \mathrm{MeOH}$ in $\mathrm{H}_{2} \mathrm{O}$. TLC running buffer consisted of $\mathrm{H}_{2} \mathrm{O} / \mathrm{MeOH} /$ glacial acetic acid/acetone/chloroform $(7: 13: 12: 15: 40)$. After running for $1 \mathrm{hr}$, TLC plates were dried and exposed on Kodak Biomax MS film (Eastman Kodak, Rochester, NY). We performed Western blots as described previously (Sanna et al., 2000) and exposed them on Kodak Biomax MS film. Autoradiograms were scanned and the signal quantified with the NIH Image 1.61 software package. Statistical analyses were performed by ANOVA with Statview software (Abacus Concepts, Calabasas, CA). Antibodies to phosphorylated Akt (Thr308) and phosphorylated p70 ${ }^{\mathrm{S} 6 \mathrm{~K}}(\mathrm{Thr} 389)$ were obtained from Cell Signaling Technology (Beverly, MA). These residues are phosphorylated in a PI3-kinase-dependent manner and are predictors of the activation of the two kinases (Alessi et al., 1996; Balendran et al., 1999). Antibodies to total Akt (Santa Cruz Biotechnology, Santa Cruz, $\mathrm{CA}$ ) and total $\mathrm{p} 70^{\mathrm{S} 6 \mathrm{~K}}$ (Cell Signaling Technology) served as controls.

\section{RESULTS}

\section{PI3-kinase and its downstream effectors are persistently activated during LTP}

We induced LTP of fEPSP at Schaffer collateral/commissural fiber-CA1 synapses in hippocampal slices with an HFS paradigm consisting of two trains of electrical stimuli of $100 \mathrm{~Hz}$ with a duration of $500 \mathrm{msec}$ each at an interval of $10 \mathrm{sec}$. The CA1 region was rapidly dissected and immediately frozen for biochemical analyses at different time points before and after delivery of LTP-inducing HFS. All slices used for biochemistry were monitored electrophysiologically. By use of a PI3-kinase assay, we observed that the activity of PI3-kinase in CA1 regions was significantly $(p<0.05)$ elevated in tetanized slices during both the post-tetanic potentiation (PTP) and LTP, 30 min after HFS (Fig. 1A). Consistently, phosphorylation of the PI3-kinase downstream effectors Akt and $\mathrm{p} 70^{\mathrm{S} 6 \mathrm{~K}}$ was also significantly $(p<0.05)$ induced during PTP and LTP (Fig. $1 B-D)$. Inhibition of PI3kinase with the specific inhibitor of PI3-kinase LY294002 (100 


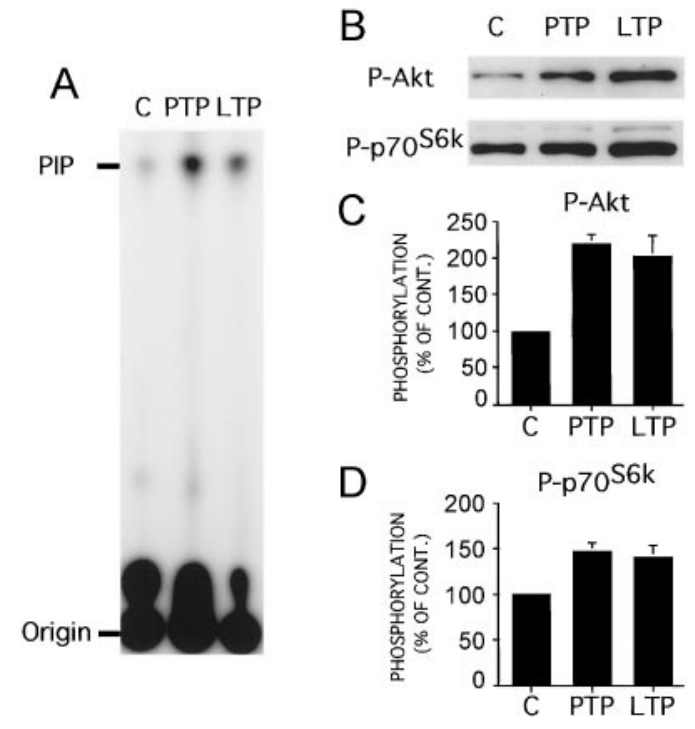

Figure 1. PI3-kinase and its downstream effectors Akt and $\mathrm{p} 70^{\mathrm{S} 6 \mathrm{~K}}$ are activated in LTP. A, PI3-kinase activity was increased after LTP-inducing HFS. PI3-kinase activity was tested in CA1 protein extracts using phosphatidylinositol as a substrate in the presence of $\left[\gamma_{-}{ }^{32} \mathrm{P}\right] \mathrm{ATP}$. Accumulation of radioactive phosphatidylinositol-3P $(P I P)$ was increased shortly after HFS $(P T P)$ and $30 \mathrm{~min}$ after HFS $(L T P)$ when compared with untetanized control slices $(C)$. $B-D$, Phosphorylation of PI3-kinase downstream effectors Akt and $\mathrm{p} 70^{\mathrm{S} 6 \mathrm{~K}}$ was also significantly increased ( $p<0.05$ for both), as revealed by Western blotting with specific phosphorylation state-specific antibodies. $C, D$, Mean phosphorylation of Akt and $\mathrm{p} 70^{\mathrm{S} 6 \mathrm{~K}}$, respectively; error bars indicate SEM. ${ }^{*} p<0.05$ indicates different from control. $E$, Incubation of hippocampal slices with the PI3-kinase-specific inhibitor LY294002 $(100 \mu \mathrm{M})$ prevented increased phosphorylation of Akt and $\mathrm{p} 70^{\mathrm{S} 6 \mathrm{~K}} 30 \mathrm{~min}$ after HFS; representative blots. $F$, Cumulative results from these experiments. ${ }^{*} p<0.05$ indicates different from basal; $\ddagger p<0.05$ indicates different from potentiated slices.

$\mu \mathrm{M})$ (Vlahos et al., 1994) prevented increased phosphorylation of Akt and p70 ${ }^{\text {S6K }}$ after HFS (Fig. $1 E, F$ ).

\section{PI3-kinase is required for LTP expression but not for the maintenance or the induction of LTP}

LTP of fEPSP was induced at Schaffer collateral/commissural fiber-CA1 synapses in hippocampal slices with the HFS paradigm described above. A 20 min bath application of the PI3kinase inhibitor LY294002 $(100 \mu \mathrm{M}) 30$ min after delivery of HFS abated established LTP of fEPSP in the tetanized pathway without affecting fEPSPs in the untetanized one of a two-pathway paradigm (Fig. $2 A)$. In these slices $(n=7)$, mean \pm SE normalized fEPSP slopes of the tetanized pathway were $171.3 \pm 2.6 \%$ of baseline before application of LY294002. During application of the drug, fEPSP slope of the tetanized pathway decreased to baseline levels $(94.5 \pm 1.0 \%)$. However, fEPSPs recovered to a potentiated level $(154.9 \pm 1.0 \%) \sim 40$ min after LY294002 washout (Fig. 2A). This result suggests that PI3-kinase activity is required for the expression rather than the maintenance of LTP. The concentration of LY294002 used here is in the high range of doses used in tissue culture (Vogelbaum et al., 1998; Akasaki et al., 1999; Cox et al., 1999; Sajan et al., 1999) in which drugeffective doses are usually lower than in slice preparations. When tested on a battery of purified ATP-requiring enzymes, including PKC, PKA, MAPK, Src, epidermal growth factor receptor, and PI4-kinase, LY294002 had no effect on the activity of any of them at a concentration of $50 \mu \mathrm{M}$, whereas its $\mathrm{IC}_{50}$ on purified PI3kinase was $1.4 \mu \mathrm{M}$ (Vlahos et al., 1994). At $100 \mu \mathrm{M}$, LY294002 did not cause cellular toxicity as measured by MTT oxidation (Vlahos et al., 1994).

To validate the specificity of the effect of LY294002 on established LTP, we tested the structurally unrelated PI3-kinase inhibitor wortmannin (Powis et al., 1994; Norman et al., 1996). Like LY294002, wortmannin (5 $\mu \mathrm{M})$ could abate established LTP in the tetanized pathway when applied $30 \mathrm{~min}$ after tetanization (Fig. 2B). In these slices, as seen with LY294002, a $20 \mathrm{~min}$ application of wortmannin reversed established LTP $(n=5)$ to baseline levels (fEPSP slope, $98.8 \pm 3.0 \%$ ). Treatment with
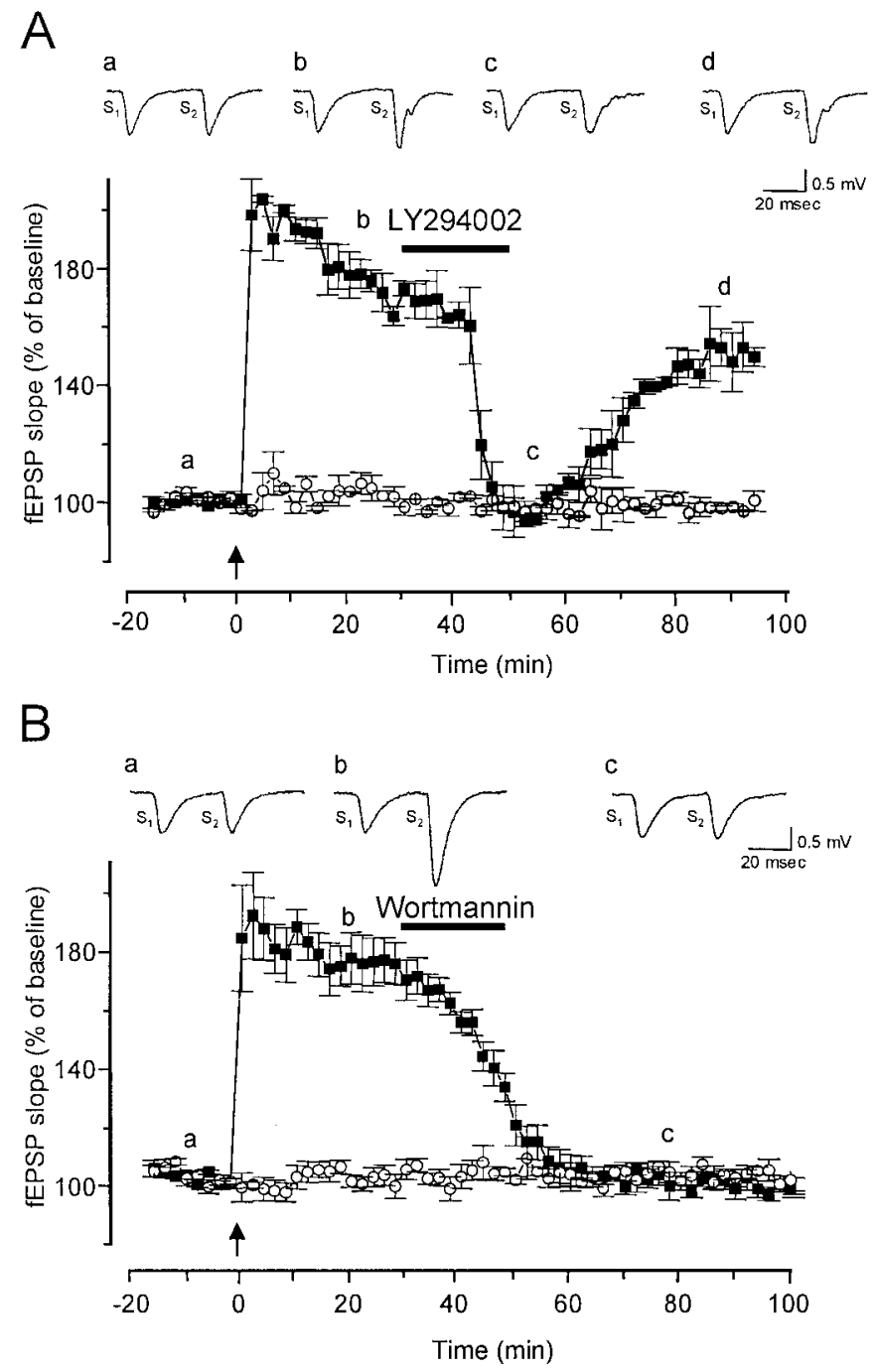

Figure 2. Inhibitors of PI3-kinase abate established LTP of fEPSP in the CA1 region. Synaptic potentials were simultaneously monitored in two independent pathways [white circles, stimulus 1 (S1); black squares, stimulus 2 (S2)]. The structurally unrelated inhibitors of PI3-kinase LY294002 $(100 \mu \mathrm{M})$ and wortmannin $(5 \mu \mathrm{M})$ were applied 30 min after delivery of HFS to one of the two pathways (S2). Insets are representative traces of extracellular fEPSPs recorded at the times marked by lowercase letters. Each representative trace is an average of five responses. Graphs represent the mean normalized fEPSP slopes plotted against time. Arrows indicate when tetanic stimulation to one pathway (black squares) was given at time 0. $A$, A transient 20 min application of LY294002 (100 $\mu \mathrm{M}) 30 \mathrm{~min}$ after LTP induction abated LTP in the potentiated pathway $(n=7)$ (black squares), but no change was seen in the untetanized pathway (white circles). $B$, Similar results were obtained with wortmannin, a structurally unrelated PI3-kinase inhibitor $(5 \mu \mathrm{M})(n=5)$. As expected, inhibition by wortmannin was irreversible. 
wortmannin did not affect fEPSP slopes in the untetanized pathway (Fig. 2B). However, whereas LY294002 is a reversible inhibitor of PI3-kinase (Vlahos et al., 1994), wortmannin is an irreversible one (Powis et al., 1994; Norman et al., 1996). Predictably, therefore, LTP expression did not recover after wortmannin withdrawal (Fig. 2B).

In hippocampal slices continuously incubated in LY294002 $(100 \mu \mathrm{M})$, no LTP of fEPSP was observed after delivery of HFS (Fig. 3A). However, if LY294002 was withdrawn 5 min after HFS, an LTP of fEPSP was seen (Fig. $3 B$ ). In fact, in these slices $(n=$ $6)$, mean \pm SE normalized fEPSP slope was $157.1 \pm 5.1 \%$ at 60 min after HFS (Fig. $3 B$ ). This result indicates that PI3-kinase activity is not required for LTP induction. As expected, pretreatment with wortmannin prevented LTP induction in the CA1, and no LTP was seen during washout (data not shown). PTP was not significantly affected by bath application of LY294002 (100 $\mu \mathrm{M})$, nor was paired-pulse facilitation, which, like PTP, is a presynaptic form of short-term plasticity (Kamiya and Zucker, 1994; Fisher et al., 1997). Intracellular recording from CA1 pyramidal neurons $(n=5)$ also demonstrated that a $20 \mathrm{~min}$ application of LY294002 $(100 \mu \mathrm{M})$ did not modify the amplitudes of NMDA glutamate receptor-mediated EPSPs pharmacologically isolated with the AMPA receptor antagonist CNQX $(10 \mu \mathrm{M})$, the $\mathrm{GABA}_{\mathrm{A}}$ receptor antagonist bicuculline $(30 \mu \mathrm{M})$, and the $\mathrm{GABA}_{\mathrm{B}}$ receptor antagonist CGP55845A (1 $\mu \mathrm{M})$ (Fig. 3C). Resting membrane potentials and input resistance were also unaffected by bath application of LY294002 (100 $\mu \mathrm{M})(n=5)$ (data not shown).

\section{PI3-kinase is required for the expression of VDCC-dependent LTP}

Activation of NMDA receptors is the primary trigger for LTP with the HFS protocol used above. In fact, although induction of LTP in this manner is prevented by the NMDA receptor antagonist D-AP-5 $(50 \mu \mathrm{M})$, it is not prevented by the L-type VDCC blocker nifedipine (30 $\mu \mathrm{M})$ (Fig. 4). Even when such a tetaniza-
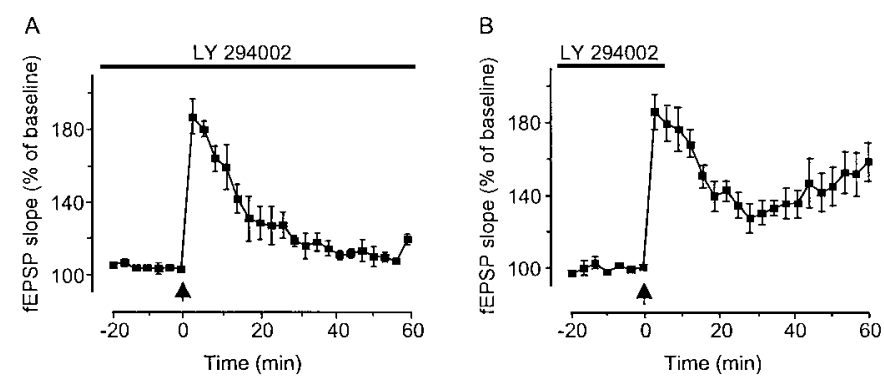

C

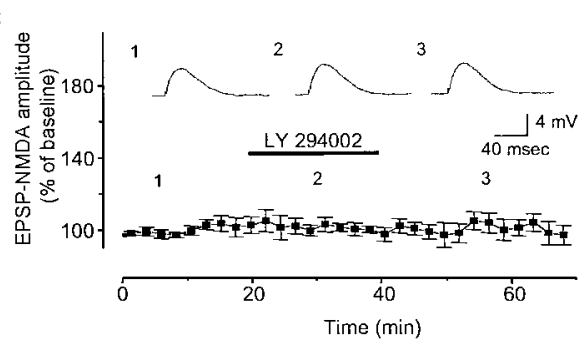

Figure 3. PI3-kinase is not required for LTP induction. A, Hippocampal slices continuously incubated in LY294002 $(100 \mu \mathrm{M})$ did not display LTP of fEPSP after delivery of HFS $(n=6)$. $B$, If LY294002 was withdrawn 5 min after HFS, an LTP of fEPSP was seen $(n=6)$. $C$, Pharmacologically isolated NMDA receptor-mediated EPSP amplitudes were not modified by a $20 \mathrm{~min}$ application of LY294002 $(100 \mu \mathrm{M})(102.2 \pm 2.5 \%)$ as revealed by intracellular recordings from CA1 pyramidal neurons $(n=5)$.
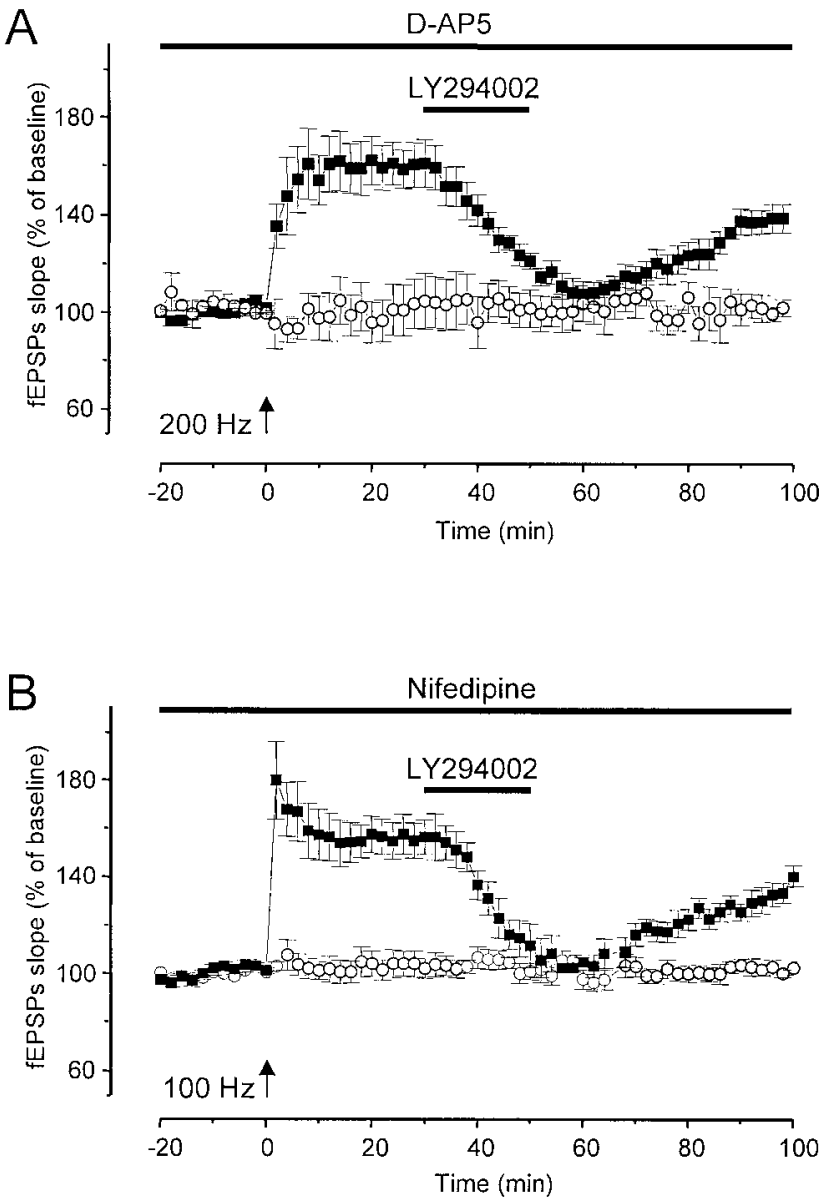

Figure 4. PI3-kinase is required for the expression of both NMDA- and VDCC-dependent forms of CA1 LTP. A, L-type VDCC-dependent form of LTP of fEPSP was induced at Schaffer collateral/commissural fiber-CA1 synapses in the presence of D-AP-5 $(50 \mu \mathrm{M})$. A $20 \mathrm{~min}$ application of LY294002 $(100 \mu \mathrm{M}) 30 \mathrm{~min}$ after the induction of VDCC-dependent LTP abated LTP in the tetanized pathway $(n=6)$ (black squares), but no change was seen in the fEPSP in the untetanized pathway (white circles). B, Inhibition of PI3-kinase with LY294002 $(100 \mu \mathrm{M})$ also abated NMDAdependent LTP induced in the presence of nifedipine $(30 \mu \mathrm{M})$.

tion protocol was delivered in the presence of nifedipine $(30 \mu \mathrm{M})$, inhibition of PI3-kinase with LY294002 (100 $\mu \mathrm{M})$ abated established LTP of fEPSP without affecting the untetanized pathway $(n=6)$ (Fig. 4). As in the experiments described above, the effect of LY294002 was reversible, and potentiation recovered during washout (Fig. 4). However, with a stronger tetanization protocol (see Materials and Methods) (Teyler et al., 1994; Grover and Yan, 1999), an L-type VDCC-dependent form of LTP can also be induced at Schaffer collateral/commissural fibers-CA1 synapses in the presence of the NMDA blocker D-AP-5 (50 $\mu \mathrm{M})$ (Teyler et al., 1994; Grover and Yan, 1999). The dependence of this LTP on VDCC is demonstrated by its sensitivity to nifedipine $(30 \mu \mathrm{M})$ (data not shown) (Teyler et al., 1994; Grover and Yan, 1999). Thus, we investigated whether inhibition of PI3-kinase could also abate such VDCC-dependent LTP. We observed that, when applied $30 \mathrm{~min}$ after induction of VDCC-dependent LTP, LY294002 $(100 \mu \mathrm{M})$ abated established potentiation of fEPSP in the tetanized pathway without affecting fEPSP slopes in the untetanized one (Fig. 4). In these slices $(n=6)$, mean \pm SE normalized fEPSP slopes of the tetanized pathway were $160.7 \pm$ $0.5 \%$ of baseline before application of LY294002 (100 $\mu \mathrm{M})$. A 20 
min bath application of LY294002 30 min after delivery of HFS abated established LTP of fEPSP to baseline levels (109.5 \pm $1.2 \%)$. The fEPSPs recovered to a potentiated level (138.5 \pm $0.7 \%$ ) 40-50 min after LY294002 washout (Fig. 4). These results suggest that PI3-kinase is required for the expression of both a strictly NMDA-dependent and a VDCC-dependent form of LTP at Schaffer collateral/commissural fiber-CA1 synapses.

\section{DISCUSSION}

We observed that PI3-kinase activity was induced during LTP of fEPSP at Schaffer collateral/commissural fiber-CA1 synapses. Two structurally unrelated PI3-kinase inhibitors, LY294002 and wortmannin, abated established LTP when applied after delivery of HFS, suggesting that PI3-kinase is involved in the maintenance-expression phase of LTP. After withdrawal of LY294002, a reversible inhibitor of PI3-kinase, fEPSPs returned to a potentiated level. Additionally, PI3-kinase activity was dispensable for LTP induction, because delivery of HFS during perfusion with LY294002 did not prevent LTP expression after washout of this inhibitor, suggesting that different signal transduction mechanisms are involved in the induction and in the expression-maintenance phases of LTP. Last, a VDCCdependent form of LTP was also reversibly abated by LY294002.

Several signal transduction pathways have been implicated in the induction of LTP in the CA1 region, including CaMKII, Src, PKC, and MAPK (Salter, 1998; Malenka and Nicoll, 1999; Winder and Sweatt, 2001). The cAMP-PKA- cAMP response element-binding protein pathway has been shown to be required for the late phase of LTP in the CA1 region (Frey et al., 1993; Bourtchuladze et al., 1994), although a role in early events can also be demonstrated in certain paradigms (Blitzer et al., 1995). However, the signal transduction events behind the maintenance-expression phase of LTP are still poorly understood (Malenka and Nicoll, 1999). In fact, although established LTP can be abated by a broad-spectrum Ser/Thr kinase inhibitor at high doses (Malinow et al., 1988), specific inhibitors of CaMKII, Src, PKC, or the ERK-MAPK pathway, although they can prevent LTP induction when applied during HFS, do not affect established LTP (Malinow et al., 1989; Ito et al., 1991; English and Sweatt, 1997; Bortolotto and Collingridge, 1998; Salter, 1998; Chen et al., 2001). Established LTP was found to be selectively abated by two inhibitors of PI3-kinase, LY294002 and wortmannin. The reversibility of the action of LY294002 on established LTP confirms that LTP maintenance and expression are distinct events, as proposed by Malinow et al. (1988), and indicates that PI3-kinase is required for the expression rather than the maintenance of LTP (Fig. 5). PI3-kinase activity was also dispensable for LTP induction. In fact, if HFS was delivered during incubation of hippocampal slices with LY294002, an LTP of fEPSP was seen during withdrawal of the drug. A necessary role for PI3-kinase in the maintenance-expression phase of LTP is corroborated by the fact that wortmannin, a PI3-kinase inhibitor structurally unrelated to LY294002, could also selectively abate established LTP. However, unlike LY294002, wortmannin blocks PI3-kinase irreversibly by covalent modification of the kinase, and, thus, PI3-kinase activity cannot recover without new protein synthesis (Powis et al., 1994; Norman et al., 1996). Therefore, wortmannin did not allow us to differentiate between LTP maintenance and expression because LTP did not recover after withdrawal of the inhibitor. Additionally, when we pretreated hippocampal slices with wortmannin, LTP in the CA1 was prevented, and the irreversible action of the drug did not allow it to recover during washout.

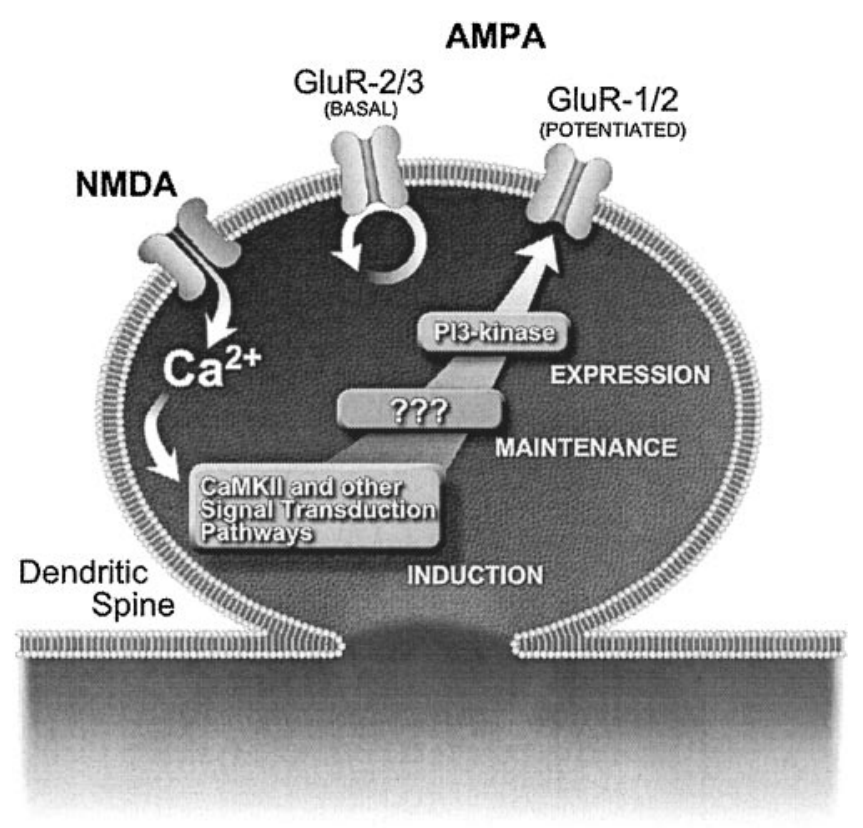

Figure 5. A model for the role of PI3-kinase in LTP. AMPA receptors composed of subunits 2 and 3 (GluR2/3) are believed to be responsible for basal AMPA responses. They are present at variable levels at postsynaptic sites in which they constitutively cycle between intracellular compartments and presynaptic membranes (Passafaro et al., 2001; Shi et al., 2001). Addition of GluR1 AMPA receptors in complex with GluR2 (GluR1/2) to postsynaptic membranes is believed to be the basis for LTP (Shi et al., 2001). We showed here that PI3-kinase is required for LTP but not for basal AMPA transmission. This observation is consistent with a role for PI3-kinase in the insertion of AMPA receptors during LTP but not in regulating basal AMPA receptor density. Consistent with this view, it has been shown recently that NMDA-dependent exocytosis of GluR1containing AMPA receptor in primary hippocampal neurons is PI3kinase dependent, unlike the exocytosis of GluR2 subunits not associated with GluR1 (Passafaro et al., 2001). Interestingly, delivery of HFS during perfusion with the reversible PI3-kinase inhibitor LY294002 did not prevent expression of LTP after washout of this inhibitor, and addition of LY294002 to established LTP caused a reversible inhibition of LTP. The former observation suggests that PI3-kinase is not responsible for the induction of LTP. The latter observation confirms that LTP maintenance and expression are distinct events (Malinow et al., 1988) and indicates that PI3-kinase activity is required for LTP expression rather than for its maintenance.

Consistently, LTP was not seen in the dentate gyrus in animals pretreated with wortmannin (Kelly and Lynch, 2000). Although the term "expression" was used in that report (Kelly and Lynch, 2000), pretreatment with an irreversible inhibitor like wortmannin does not allow one to distinguish between inhibition of LTP induction and of the maintenance-expression phase of LTP. Recently, preincubation with inhibitors of PI3-kinase was also shown to prevent LTP of fEPSP in the basolateral amygdala (Lin et al., 2001).

We then investigated whether the expression of LTP induced with a different triggering mechanism at Schaffer collateral/commissural fiber-CA1 synapses would also display the same PI3kinase dependence. As mentioned above, we observed that activation of PI3-kinase with our standard HFS paradigm was dependent on NMDA receptors rather than VDCC. Consistently, we observed that a strictly NMDA-dependent LTP induced in the presence of nifedipine was reversibly abated by the PI3-kinase inhibitor LY294002. We then investigated whether LY294002 could also reversibly abate a form of VDCC- 
dependent LTP at Schaffer collateral/commissural fiber-CA1 synapses. In fact, activation of VDCC can induce an LTP that, perhaps because of the extrasynaptic localization of VDCC, appears to recruit a different set of signal transduction pathways than those required for NMDA-dependent LTP (Cavus and Teyler, 1996). However, we observed that VDCC-dependent LTP induced by strong tetanization in the presence of D-AP-5 was reversibly abated by LY294002, like NMDA-dependent LTP. This result raises the possibility that PI3-kinase could be a final common pathway for the expression of multiple forms of synaptic potentiation.

It is believed currently that central to synaptic plasticity are dynamic modifications of dendritic spines leading to changes in the density of AMPA receptors on postsynaptic membranes (Malenka and Nicoll, 1999; Luscher et al., 2000; Malinow et al., 2000) (but see Grosshans et al., 2002). Cytoskeletal elements such as actin have been implicated in regulating spine morphology (Halpain, 2000; Matus, 2000) and AMPA redistribution (Allison et al., 1998; Shen et al., 2000). Mounting evidence supports that PI3-kinase and its effectors are part of the actin polymerizing system in several cell types, including neurons (Wymann and Arcaro, 1994; Higaki et al., 1996; Burnett et al., 1998). PI3-kinase has also been shown to be involved in multiple aspects of membrane trafficking in different cell types. Among them is the surface translocation of glucose transporters (Corvera and Czech, 1998), $\mathrm{Na}^{+} / \mathrm{H}^{+}$exchanger (Kurashima et al., 1998; Janecki et al., 2000; Yudowski et al., 2000), and transferrin receptor (Shepherd et al., 1995), all of which cycle between the plasmalemma and intracellular membrane compartments. Thus, PI3kinase could play a role in the cytoskeletal and signaling events responsible for regulating AMPA receptor density at postsynaptic sites. AMPA receptors of different subunit composition appear to be responsible for basal AMPA responses and for the increased AMPA-mediated transmission seen in LTP (Shi et al., 1999; Luscher et al., 2000; Malinow et al., 2000; Shi et al., 2001). AMPA receptors in the hippocampus are mostly hetero-oligomers composed of GluR1/GluR2 or GluR2/GluR3 subunits (Wenthold et al., 1996). GluR2/3 AMPA receptors are present at variable levels at postsynaptic sites, and they constitutively cycle between intracellular compartments and presynaptic membranes through the interaction of GluR2 with $N$-ethylmaleimide-sensitive factor and group II PDZ (postsynaptic density-95/Discs large/zona occludens-1) domain proteins (Sheng and Pak, 2000; Passafaro et al., 2001; Shi et al., 2001). AMPA receptors containing subunits 1 and $2($ GluR1/2) are delivered to postsynaptic sites after LTP induction through the interaction of GluR1 and group I PDZ domain proteins (Shi et al., 2001). Some synapses are believed to lack AMPA receptors, the so-called "silent synapses," and to be converted to functional synapses during LTP (Malenka and Nicoll, 1999; Luscher et al., 2000). We observed that PI3-kinase inhibitors can abate LTP but do not affect basal AMPA transmission. This suggests a requirement of PI3-kinase for the insertion and/or continued surface expression of additional AMPA receptors during LTP but not for regulating basal AMPA receptor density (Fig. 5). Consistent with this view, it has been shown recently that exocytosis of GluR1-containing AMPA receptor can be induced in primary hippocampal neurons by NMDA or insulin in a PI3-kinase-dependent manner (Passafaro et al., 2001). However, exocytosis of GluR2 subunits not associated with GluR1 in primary hippocampal neurons is unaffected by the PI3-kinase inhibitor wortmannin (Passafaro et al., 2001).

The present data demonstrate that PI3-kinase is required for the expression but not for the induction or maintenance of LTP at Schaffer collateral/commissural fiber-CA1 synapses. Although several signal transduction pathways are known to be involved in the induction of LTP, PI3-kinase is the first one to be found to be required for its expression. Both NMDA-dependent and VDCCdependent forms of LTP at Schaffer collateral/commissural fiber-CA1 synapses were found to require PI3-kinase activity for their expression, suggesting that PI3-kinase could be a final common pathway in the expression of multiple forms of synaptic potentiation.

\section{REFERENCES}

Abraham WC, Gustafsson B, Wigstrom H (1987) Long-term potentiation involves enhanced synaptic excitation relative to synaptic inhibition in guinea-pig hippocampus. J Physiol (Lond) 394:367-380.

Akasaki T, Koga H, Sumimoto H (1999) Phosphoinositide 3-kinasedependent and -independent activation of the small GTPase Rac2 in human neutrophils. J Biol Chem 274:18055-18059.

Alessi DR, Andjelkovic M, Caudwell B, Cron P, Morrice N, Cohen P, Hemmings BA (1996) Mechanism of activation of protein kinase B by insulin and IGF-1. EMBO J 15:6541-6551.

Allison DW, Gelfand VI, Spector I, Craig AM (1998) Role of actin in anchoring postsynaptic receptors in cultured hippocampal neurons: differential attachment of NMDA versus AMPA receptors. J Neurosci 18:2423-2436.

Balendran A, Currie R, Armstrong CG, Avruch J, Alessi DR (1999) Evidence that 3-phosphoinositide-dependent protein kinase-1 mediates phosphorylation of p70 S6 kinase in vivo at Thr-412 as well as Thr-252. J Biol Chem 274:37400-37406.

Blitzer RD, Wong T, Nouranifar R, Iyengar R, Landau EM (1995) Postsynaptic cAMP pathway gates early LTP in hippocampal CA1 region. Neuron 15:1403-1414.

Bortolotto ZA, Collingridge GL (1998) Involvement of calcium/ calmodulin-dependent protein kinases in the setting of a molecular switch involved in hippocampal LTP. Neuropharmacology 37:535-544.

Bourtchuladze R, Frenguelli B, Blendy J, Cioffi D, Schutz G, Silva AJ (1994) Deficient long-term memory in mice with a targeted mutation of the cAMP-responsive element-binding protein. Cell 79:59-68.

Burnett PE, Blackshaw S, Lai MM, Qureshi IA, Burnett AF, Sabatini DM, Snyder SH (1998) Neurabin is a synaptic protein linking p70 S6 kinase and the neuronal cytoskeleton. Proc Natl Acad Sci USA 95:8351-8356.

Cavus I, Teyler T (1996) Two forms of long-term potentiation in area CA1 activate different signal transduction cascades. J Neurophysiol 76:3038-3047.

Chan TO, Rittenhouse SE, Tsichlis PN (1999) AKT/PKB and other D3 phosphoinositide-regulated kinases: kinase activation by phosphoinositide-dependent phosphorylation. Annu Rev Biochem 68:965-1014

Chen HX, Otmakhov N, Strack S, Colbran RJ, Lisman JE (2001) Is persistent activity of calcium/calmodulin-dependent kinase required for the maintenance of LTP? J Neurophysiol 85:1368-1376.

Chou MM, Hou W, Johnson J, Graham LK, Lee MH, Chen CS, Newton AC, Schaffhausen BS, Toker A (1998) Regulation of protein kinase C zeta by PI 3-kinase and PDK-1. Curr Biol 8:1069-1077.

Clapham DE (1995) Calcium signaling. Cell 80:259-268.

Corvera S, Czech MP (1998) Direct targets of phosphoinositide 3 -kinase products in membrane traffic and signal transduction. Trends Cell Biol 8:442-446.

Cox D, Tseng CC, Bjekic G, Greenberg S (1999) A requirement for phosphatidylinositol 3-kinase in pseudopod extension. J Biol Chem 274:1240-1247.

English JD, Sweatt JD (1997) A requirement for the mitogen-activated protein kinase cascade in hippocampal long term potentiation. J Biol Chem 272:19103-19106.

Fisher SA, Fischer TM, Carew TJ (1997) Multiple overlapping processes underlying short-term synaptic enhancement. Trends Neurosci 20:170-177.

Franke TF, Kaplan DR, Cantley LC (1997) PI3K: downstream AKTion blocks apoptosis. Cell 88:435-437.

Frey U, Huang YY, Kandel ER (1993) Effects of cAMP simulate a late stage of LTP in hippocampal CA1 neurons. Science 260:1661-1664.

Grosshans DR, Clayton DA, Coultrap SJ, Browning MD (2002) LTP leads to rapid surface expression of NMDA but not AMPA receptors in adult rat CA1. Nat Neurosci 5:27-33.

Grover LM, Yan C (1999) Blockade of GABAA receptors facilitates induction of NMDA receptor-independent long-term potentiation. J Neurophysiol 81:2814-2822.

Halpain S (2000) Actin and the agile spine: how and why do dendritic spines dance? Trends Neurosci 23:141-146.

Higaki M, Sakaue H, Ogawa W, Kasuga M, Shimokado K (1996) Phos- 
phatidylinositol 3-kinase-independent signal transduction pathway for platelet-derived growth factor-induced chemotaxis. J Biol Chem 271:29342-29346.

Huang EP (1998) Synaptic plasticity: going through phases with LTP. Curr Biol 8:R350-R352.

Ito I, Hidaka H, Sugiyama H (1991) Effects of KN-62, a specific inhibitor of calcium/calmodulin-dependent protein kinase II, on long-term potentiation in the rat hippocampus. Neurosci Lett 121:119-121.

Janecki AJ, Janecki M, Akhter S, Donowitz M (2000) Basic fibroblast growth factor stimulates surface expression and activity of $\mathrm{Na}^{+} / \mathrm{H}^{+}$ exchanger NHE3 via mechanism involving phosphatidylinositol 3-kinase. J Biol Chem 275:8133-8142.

Kamiya H, Zucker RS (1994) Residual $\mathrm{Ca}^{2+}$ and short-term synaptic plasticity. Nature 371:603-606.

Kelly A, Lynch MA (2000) Long-term potentiation in dentate gyrus of the rat is inhibited by the phosphoinositide 3-kinase inhibitor, wortmannin. Neuropharmacology 39:643-651.

Kurashima K, Szabo EZ, Lukacs G, Orlowski J, Grinstein S (1998) Endosomal recycling of the $\mathrm{Na}^{+} / \mathrm{H}^{+}$exchanger $\mathrm{NHE} 3$ isoform is regulated by the phosphatidylinositol 3-kinase pathway. J Biol Chem 273:20828-20836.

Leevers SJ, Vanhaesebroeck B, Waterfield MD (1999) Signalling through phosphoinositide 3-kinases: the lipids take centre stage. Curr Opin Cell Biol 11:219-225.

Lin C, Yeh S, Lu K, Leu T, Chang W, Gean P (2001) A role for the pi-3 kinase signaling pathway in fear conditioning and synaptic plasticity in the amygdala. Neuron 31:841-851.

Luscher C, Nicoll RA, Malenka RC, Muller D (2000) Synaptic plasticity and dynamic modulation of the postsynaptic membrane. Nat Neurosci 3:545-550.

Macara IG, Marinetti GV, Balduzzi PC (1984) Transforming protein of avian sarcoma virus UR2 is associated with phosphatidylinositol kinase activity: possible role in tumorigenesis. Proc Natl Acad Sci USA 81:2728-2732.

Malenka RC, Nicoll RA (1999) Long-term potentiation-a decade of progress? Science 285:1870-1874.

Malinow R, Madison DV, Tsien RW (1988) Persistent protein kinase activity underlying long-term potentiation. Nature 335:820-824.

Malinow R, Schulman H, Tsien RW (1989) Inhibition of postsynaptic PKC or CaM KII blocks induction but not expression of LTP. Science 245:862-866.

Malinow R, Mainen ZF, Hayashi Y (2000) LTP mechanisms: from silence to four-lane traffic. Curr Opin Neurobiol 10:352-357.

Matus A (2000) Actin-based plasticity in dendritic spines. Science 290:754-758.

Norman BH, Shih C, Toth JE, Ray JE, Dodge JA, Johnson DW, Rutherford PG, Schultz RM, Worzalla JF, Vlahos CJ (1996) Studies on the mechanism of phosphatidylinositol 3-kinase inhibition by wortmannin and related analogs. J Med Chem 39:1106-1111.

Passafaro M, Piëch V, Sheng M (2001) Subunit-specific temporal and spatial patterns of AMPA receptor exocytosis in hippocampal neurons. Nat Neurosci 4:917-926.

Powis G, Bonjouklian R, Berggren MM, Gallegos A, Abraham R, Ashendel C, Zalkow L, Matter WF, Dodge J, Grindey G, Vlahos CJ (1994)
Wortmannin, a potent and selective inhibitor of phosphatidylinositol-3kinase. Cancer Res 54:2419-2423.

Romanelli A, Martin KA, Toker A, Blenis J (1999) p70 S6 kinase is regulated by protein kinase Czeta and participates in a phosphoinositide 3-kinase-regulated signalling complex. Mol Cell Biol 19:2921-2928.

Sajan MP, Standaert ML, Bandyopadhyay G, Quon MJ, Burke Jr TR, Farese RV (1999) Protein kinase C-zeta and phosphoinositidedependent protein kinase-1 are required for insulin-induced activation of ERK in rat adipocytes. J Biol Chem 274:30495-30500.

Salter MW (1998) Src, $N$-methyl-D-aspartate (NMDA) receptors, and synaptic plasticity. Biochem Pharmacol 56:789-798.

Sanna PP, Berton F, Cammalleri M, Tallent MK, Siggins GF, Bloom FE, Francesconi W (2000) A role for Src kinase in spontaneous epileptiform activity in the CA3 region of the hippocampus. Proc Natl Acad Sci USA 97:8653-8657.

Shen L, Liang F, Walensky LD, Huganir RL (2000) Regulation of AMPA receptor GluR1 subunit surface expression by a $4.1 \mathrm{~N}$-linked actin cytoskeletal association. J Neurosci 20:7932-7940.

Sheng M, Pak DT (2000) Ligand-gated ion channel interactions with cytoskeletal and signaling proteins. Annu Rev Physiol 62:755-778.

Shepherd PR, Nave BT, Siddle K (1995) Involvement of PI 3-kinase in stimulation of glucose transport and recruitment of transferrin receptors in 3T3-L1 adipocytes. Biochem Soc Trans 23:201S.

Shi S, Hayashi Y, Esteban JA, Malinow R (2001) Subunit-specific rules governing AMPA receptor trafficking to synapses in hippocampal pyramidal neurons. Cell 105:331-343.

Shi SH, Hayashi Y, Petralia RS, Zaman SH, Wenthold RJ, Svoboda K, Malinow R (1999) Rapid spine delivery and redistribution of AMPA receptors after synaptic NMDA receptor activation. Science 284:1811-1816.

Teyler TJ, Cavus I, Coussens C, DiScenna P, Grover L, Lee YP, Little Z (1994) Multideterminant role of calcium in hippocampal synaptic plasticity. Hippocampus 4:623-634

Vlahos CJ, Matter WF, Hui KY, Brown RF (1994) A specific inhibitor of phosphatidylinositol 3-kinase, 2-(4-morpholinyl)-8-phenyl-4H-1benzopyran-4-one (LY294002). J Biol Chem 269:5241-5248.

Vogelbaum MA, Tong JX, Rich KM (1998) Developmental regulation of apoptosis in dorsal root ganglion neurons. J Neurosci 18:8928-8935.

Wenthold RJ, Petralia RS, Blahos II J, Niedzielski AS (1996) Evidence for multiple AMPA receptor complexes in hippocampal CA1/CA2 neurons. J Neurosci 16:1982-1989.

Whitman M, Downes CP, Keeler M, Keller T, Cantley L (1988) Type I phosphatidylinositol kinase makes a novel inositol phospholipid, phosphatidylinositol-3-phosphate. Nature 332:644-646.

Winder DG, Sweatt JD (2001) Roles of serine/threonine phosphatases in hippocampal synaptic plasticity. Nat Rev Neurosci 2:461-474.

Wymann M, Arcaro A (1994) Platelet-derived growth factor-induced phosphatidylinositol 3-kinase activation mediates actin rearrangements in fibroblasts. Biochem J 298:517-520.

Wymann MP, Pirola L (1998) Structure and function of phosphoinositide 3-kinases. Biochim Biophys Acta 1436:127-150.

Yudowski GA, Efendiev R, Pedemonte CH, Katz AI, Berggren PO, Bertorello AM (2000) Phosphoinositide-3 kinase binds to a prolinerich motif in the $\mathrm{Na}^{+}, \mathrm{K}^{+}$-ATPase alpha subunit and regulates its trafficking. Proc Natl Acad Sci USA 97:6556-6561. 